\title{
Leukoencephalopathy-dystonia-motor neuropathy syndrome
}

INSERM

\section{Source}

INSERM. (1999). Orphanet: an online rare disease and orphan drug data base. Leukoencephalopathy-dystonia-motor neuropathy syndrome. ORPHA:163684

Leukoencephalopathy-dystonia-motor neuropathy syndrome is a peroxisomal neurodegenerative disorder characterized by spasmodic torticollis, dystonic head tremor, intention tremor, nystagmus, hyposmia, and hypergonadotrophic hypogonadism with azoospermia. Slight cerebellar signs (left-sided intention tremor, balance and gait impairment) are also noted. Magnetic resonance imaging (MRI) shows bilateral hyperintense signals in the thalamus, butterfly-like lesions in the pons, and lesions in the occipital region, whereas nerve conduction studies of the lower extremities shows a predominantly motor and slight sensory neuropathy. 